\title{
Low incidence of UPD in spontaneous abortions beyond the 5th gestational week
}

\author{
Barbara Fritz ${ }^{* 1}$, Mücevher Aslan ${ }^{1}$, Vera Kalscheuer ${ }^{2}$, Mette Ramsing ${ }^{1}$, Kathrin Saar ${ }^{3}$, \\ Brigitte Fuchs ${ }^{1}$ and Helga Rehder ${ }^{1}$
}

${ }^{1}$ Institute of Clinical Genetics, Philipps-Universität, Marburg, Germany; ${ }^{2}$ Department of Human Genetics, University Hospital Nijmegen, Netherlands; ${ }^{3}$ Max-Delbrück-Center for Molecular Medicine, Gene Mapping Center, Berlin, Germany

Approximately $15-20 \%$ of all clinically recognised pregnancies abort, most commonly between $8-12$ gestational weeks. While the majority of early pregnancy losses is attributed to cytogenetic abnormalities, the aetiology of approximately $\mathbf{4 0 \%}$ of early abortions remains unclear. To determine additional factors causing spontaneous abortions we retrospectively searched for uniparental disomies (UPD) in 77 cytogenetically normal diploid spontaneous abortions. In all cases an unbalanced chromosome anomaly was ruled out by cytogenetic investigation of chorionic/amniotic membranes and/or chorionic villi. For UPD screening microsatellite analyses were performed on DNA of abortion specimens and parental blood using highly polymorphic markers showing UPD in two cases. The distribution of markers analysed indicated maternal heterodisomy for chromosome 9 (UPhD(9)mat) in case 1 and paternal isodisomy for chromosome 21 (UPiD(21)pat) in case 2. The originating mechanism suggested was monosomy complementation in UPiD(21)pat and trisomy rescue in UPhD(9)mat. In the case of UPhD(9)mat purulent chorioamnionitis was noted and a distinctly growth retarded embryo of $3 \mathrm{~cm}$ crown-rump length showing no gross external malformations. Histological analysis in the case of UPiD(21)pat suggested a primary anlage defect. Our results indicate that less than $3 \%$ of genetically unexplained pregnancy wastage is associated with total chromosome UPD. UPD may contribute to anlage defects of human conception. Chromosome aneuploidy correction can occur in very early cleavage stages. More research, however, ought to be performed into placental mosaicism to further clarify timing and mechanisms involved in foetal UPD. European Journal of Human Genetics (2001) 9, 910-916.

Keywords: uniparental disomy; spontaneous abortions; paternal isodisomy 21; maternal heterodisomy 9

\section{Introduction}

Uniparental disomy (UPD) describes the inheritance of both homologues of a chromosome pair from only one parent. Non-disjunction may occur at first meiosis and would cause total heterodisomy (presence of both homologues from only

*Correspondence: B Fritz, Institut für Klinische Genetik am Zentrum für Humangenetik, Philipps-Universität, Bahnhofstrasse 7, D-35033

Marburg, Germany. Tel: +49 6421 2866703; Fax: +49 6421 2863984; E-mail: fritzb@mailer.uni-marburg.de

Received 28 June 2001; revised 7 September 2001; accepted 19 October 2001 one parent), whereas non-disjunction at second meiotic division would result in total isodisomy (two copies of one homologue). However, exchanges during meiosis I may introduce regions of isodisomy into a primary heterodisomic situation, thus resulting in adjacent regions of iso- and heterodisdomy. Several mechanisms can lead to UPD in connection with meiotic or mitotic non-disjunction errors. These mechanisms are regarded to be corrective for aneuploidy and include gamete complementation, monosomy complementation, trisomy rescue, and postfertilisation error. ${ }^{1,2}$ High rates of aneuploidy of up to $18 \%$ in oocytes but only $3-4 \%$ in spermatocytes ${ }^{3,4}$ lead to the assumption that 
maternal UPD could be fairly common with trisomy rescue as the most likely mechanism, therefore possibly bearing relevance for prenatal diagnosis in pregnancies with trisomy mosaicism. Thus far, trisomy rescue has been documented in cases with confined placental trisomy and uniparental disomy in the foetus. ${ }^{5-7}$

UPD has been reported for all human chromosomes with the exception of chromosomes 12, 18, and 19. Various mechanisms have been considered to cause abnormal phenotypes by UPD: loss of heterozygosity in the presence of an autosomal recessive mutation, imprinting effects, hidden mosaic trisomies in the proband or confined placental trisomy with foetal UPD ensuing trisomy rescue. In addition, UPD of X-chromosomes can cause father to son transmission of X-chromosomal disorders or homozygosity of mutated Xchromosomal genes. ${ }^{2,8}$ Observations of UPDs in humans and mice imply that many known imprinted genes, like Igf2, Igf2r, H19, have effects on placental growth or foetal development. Two imprinted genes have been shown to have a specific role in placental development and growth. Mash2 regulates the development of the spongiotrophoblast, whereas Igf2 is specifically expressed in the labyrithine trophoblast. ${ }^{9}$

It is generally accepted that as few as $30 \%$ of all human conceptions survive till birth with the large majority of these failures lost at very early stages of pregnancy. Currently published data estimate an incidence of chromosome abnormalities in first trimester spontaneous abortions of approximately $70 \% .{ }^{10}$ Trisomy is the predominant chromosome anomaly accounting for more than $50 \%$ of all abnormal abortions. In contrast, autosomal monosomies have rarely been reported. Since the mechanisms of non-disjunction lead to one gamete with an extra chromosome and one deficient of a chromosome, equal numbers of autosomal trisomies and monosomies should be expected. Studies on preimplantation embryos confirm that monosomy occurs as often as trisomy for most chromosomes. ${ }^{11}$ Thus, the nullisomic gamete seems to be at no disadvantage at the time of fertilisation. Yet the monosomic conceptus is prone to very early loss. Experimental data in mice point into the same direction with similar rates of monosomy and trisomy in the early preimplantation embryo, but with only trisomic conceptuses surviving longer periods of time. ${ }^{12}$ This led to speculations that besides UPDs from trisomy rescues there could also be a higher incidence of UPD in human abortions resulting from monosomy complementation as a further attempt to rescue a developing foetus from a lethal abnormality. In order to investigate incidences and mechanisms of UPD, we, therefore, determined the parental origin of all chromosomes in a consecutive series of 77 spontaneous abortions with normal karyotypes.

\section{Material and methods} Study group

In a cytogenetic study on spontaneous abortions, foetal derived material as well as parental blood samples had been collected over a period of 4 years. All abortions were karyotyped. Seventy-seven spontaneous abortions showing normal karyotypes were selected as UPD study population. Cytogenetic analysis was performed on chorionic villi in 43 cases, on chorionic villi and amniotic membranes in 32 cases, and on amniotic membranes in two cases. Using long term cultures primarily extraembryonic mesodermal cells were investigated which are more likely to reflect the true foetal cytogenetic status. Fifteen metaphases were minimally analysed from each case. Gestational ages ranged from 6 to 22 weeks with a peak occurrence between 8 and 12 gestational weeks (73 early abortions $\leqslant 16$. g. w./4 abortions $>16-22$ g. w.). Three cases had been identified as twin pregnancies by ultrasound.

After careful dissection of decidua, blood clots and mucus, $50-200 \mathrm{mg}$ of chorionic villi were deep frozen $\left(-80^{\circ} \mathrm{C}\right)$ for DNA extraction. Remaining samples underwent conventional cytogenetic and histological examination.

\section{Molecular analysis}

DNA was extracted from frozen foetal tissues and parental blood by standard procedures. Microsatellite polymorphisms were analysed to determine parental origin of chromosomes. A minimum of 137 markers distributed among all 22 autosomes and the X-chromosome (131 autosomal and 7 $\mathrm{X}$-linked) were amplified from the genomic DNA of each family member. In cases of uninformative individual chromosomes further testing was performed using random polymorphic markers for the respective chromosome until holochromosomic UPD could be excluded. A list of polymorphic loci and primer sequences used is available on request. Amplifications were performed under standard conditions. To carry out these large-scale studies highthroughput instrumentation and assays with high accuracy and sensitivity were required. PCR amplicons of 57 families were separated on the MegaBACE-1000 96 capillary array electrophoresis instrument and analysed with MegaBACE Genetic Profiler v.1.1 software (Amersham Pharmacia Biotech, Buckinghamshire, UK). PCR products of 20 families were analysed by separation according to their length on polyacrylamide gel electrophoresis visualised by silver staining. The inheritance of each chromosome was determined by comparing the genotypes obtained from abortion and parental DNA. Absence of UPD was confirmed by at least two informative markers showing maternal and paternal inheritance of homologue chromosomes. Determination of UPD was based on at least two informative markers. No attempt was made to identify or exclude segmental UPD. All parents had given their informed consent to the examination.

\section{Results}

All 77 spontaneous abortions with normal karyotypes that had been subjected to a systematic search for uniparental 
disomy were informative for all chromosomes, but $15 / 77$ of the families required an extended screening with additional chromosome specific markers.

However, six of the 77 cases had to be excluded from further evaluation:

(a) three cases with a genotype consistent with nonpaternity;

(b) two cases with paternally inherited alleles only verifying a complete hydatidiform mole in one singleton and one of the three twin pregnancies;

(c) one case with evidence of maternal cell contamination diagnosed by cytogenetic analysis as 46,XX. However, Y specific loci could be demonstrated marking a male genotype. The cytogenetic diagnosis, therefore, reflected the growth of contaminating maternal cells.

Thus, the final data set consisted of 71 cases of chromosomally normal spontaneous abortions. The sex ratio was $1.15(38 \times 46, \mathrm{XY}: 33 \times 46, \mathrm{XX})$ and mean gestational week at foetal loss was 11.78 (range $6-22$ ). The mean maternal age of women of the UPD negative cases were $30.5 \pm 7.8$ years (range 19-40). The majority of abortions (47.9\%) were derived from women being 25-30 years old. $40.5 \%$ of women were older than 30 years, but only $11.6 \%$ were younger than 25 years. The mean maternal ages of the UPD negative cases, however, did not differ significantly from that of chromosomally abnormal abortions. ${ }^{10}$ Histological slides of the placenta were available of all specimens. Four chorionic sacs without embryo ('blighted ovum'), five cases with partial hydatidiform moles, 52 cases with degenerative changes, hydropic villi with arrested ramification and 19 cases with normal placental development were found. A primary anlage defect was determined in $62.3 \%$.

Two of the 71 spontaneous abortions (2.8\%) tested positive for UPD:

Case 1 displayed maternal heterodisomy 9 (UPhD(9)mat) in a first conception of a 28-year-old woman and her 29-yearold husband. Spontaneous abortion had occurred at 12 gestational weeks. Histological analysis revealed purulent chorioamnionitis and slightly decreased ramification of the chorionic villi. The organised embryo of $3 \mathrm{~cm}$ crown-rump length displayed no gross external malformations, but ultrasound examination had shown 2 weeks growth retardation. Cytogenetic examination of placental tissues revealed a non-mosaic 46,XY karyotype in 15 metaphases. Markers GATA62F03, D9S925 and D9S394 showed no paternal alleles. All remaining markers demonstrated a heterozygous state thus confirming maternal heterodisomy 9 (Figure 1, Table 1). However, based on the distance of the markers tested, segmental isodisomy cannot be ruled out.

Case 2 showed paternal uniparental isodisomy for chromosome 21 (UPiD(21)pat). The mother was a 40-year-old gravida 2 , para 0 . The father was 42 years old. Missed abortion was
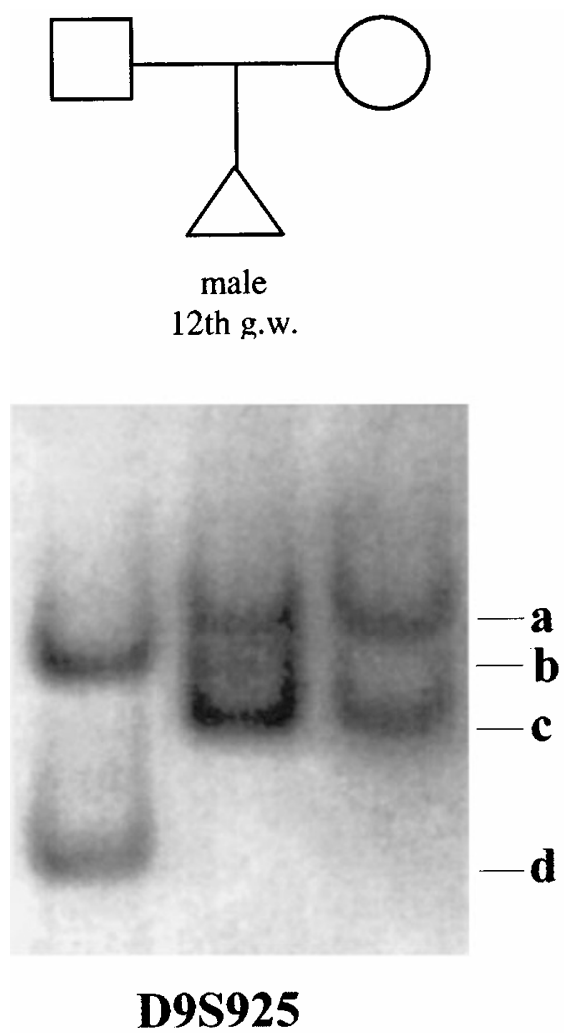

Figure 1 PCR amplification of the D9S925 microsatellite locus showing two maternal alleles, but no paternal allele in the abortion.

Table 1 Results of STR typing in the maternal UPD(9) family

\begin{tabular}{lccccc}
\hline Locus & cM & Heterozygosity & Father & $\begin{array}{c}\text { Genotypes } \\
\text { Abortion }\end{array}$ & Mother \\
\hline GATA62F03 & 5 & 0.64 & $\mathbf{b}, \mathbf{b}$ & $\mathbf{a}, \mathbf{c}$ & $\mathbf{a , c}$ \\
D9S925 & 26.5 & 0.82 & $\mathbf{b}, \mathbf{d}$ & $\mathbf{a}, \mathbf{c}$ & $\mathbf{a}, \mathbf{c}$ \\
D9S301 & 62.1 & 0.80 & a,b & a,c & a,c \\
D9S922 & 74.3 & 0.78 & b,c & a,b & a,b \\
D9S938 & 106.8 & 0.79 & a,b & a,c & a,c \\
D9S934 & 124.5 & 0.76 & a,b & c,c & c,c \\
D9S158 & 158.8 & 0.68 & a,b & a,b & a,b \\
\hline
\end{tabular}

Data from markers other than chromosome 9 are not shown. Markers location are according to GDB and Genethon linkage analysis. Informative loci for maternal uniparental heterodisomy are in bold.

diagnosed at 8 weeks of gestation. Histology revealed focal hydrops and fibrosis of the placenta with chorionic villi showing decreased ramification and vascularisation. Cytogenetic analysis suggested a normal female karyotype but DNA analysis verified UtpD(21)pat. Seven polymorphic loci on chromosome 21 were analysed, two markers (D21S1435, D21S1446) were informative showing no maternally but only paternally inherited alleles (Figure 2, Table 2). In none of the markers tested, heterozygosity could be demonstrated. Thus, 


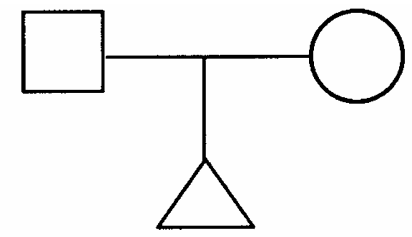

female

8th g.w.

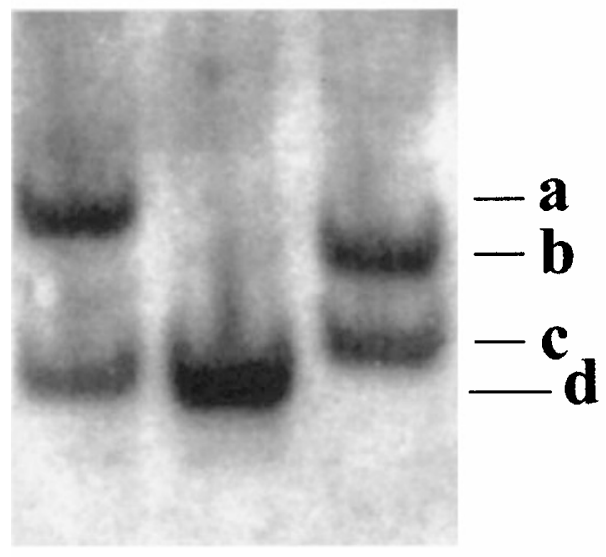

D21S1446

Figure 2 PCR amplification of the D21S1446 microsatellite showing no maternal inheritance and reduction of heterozygosity to homozygosity in the abortion.

Table 2 Marker genotypes for chromosome 21

\begin{tabular}{lrcccc}
\hline Locus & cM & Heterozygosity & Father & $\begin{array}{c}\text { Cenotypes } \\
\text { Abortion }\end{array}$ & Mother \\
\hline D21S1432 & 0.0 & 0.63 & $\mathrm{~b}, \mathrm{~b}$ & $\mathrm{~b}, \mathrm{~b}$ & $\mathrm{a}, \mathrm{b}$ \\
D21S1437 & 8.7 & 0.73 & $\mathrm{a}, \mathrm{b}$ & $\mathrm{b}, \mathrm{b}$ & $\mathrm{b}, \mathrm{c}$ \\
D21S1435 & 18.1 & 0.81 & $\mathrm{a}, \mathrm{c}$ & $\mathbf{a}, \mathbf{a}$ & $\mathbf{b}, \mathbf{b}$ \\
D21S1270 & 22.7 & 0.83 & $\mathrm{a}, \mathrm{c}$ & $\mathrm{c}, \mathrm{c}$ & $\mathrm{b}, \mathrm{c}$ \\
D21S156 & 31.9 & 0.74 & $\mathrm{a}, \mathrm{a}$ & $\mathrm{a}, \mathrm{a}$ & $\mathrm{a}, \mathrm{a}$ \\
D21S1440 & 37.9 & 0.92 & $\mathrm{a}, \mathrm{a}$ & $\mathrm{a}, \mathrm{a}$ & $\mathrm{a}, \mathrm{b}$ \\
D21S1446 & 55.3 & 0.69 & $\mathrm{a}, \mathbf{d}$ & $\mathbf{d}, \mathbf{d}$ & $\mathbf{b}, \mathbf{c}$ \\
\hline
\end{tabular}

Loci ordered from centromere to telomere are shown according to GDB and Genethon linkage analysis. Informative loci for paternal uniparental isodisomy 21 are in bold. The alleles are denoted arbitrarily ' $a-d$ ' according to their molecular size.

the conceptus was isodisomic for the main part of the chromosome 21 , this being consistent with a postzygotic monosomy rescue mechanism.

\section{Discussion}

Clinical consequences of UPD during the early embryonic development are widely unknown and early intrauterine demise of the conceptus may possibly represent the most deleterious effect. Moreover, few figures exist about the true incidence of UPD in early spontaneous abortions. So far, only four such studies have been performed. No case of UPD was detected in 35 and in 18 first trimester spontaneous abortions, respectively. ${ }^{13,14}$ Henderson et al ${ }^{15}$ identified two cases of maternal uniparental heterodisomy for chromosome 21 in 23 cases of early embryonic losses - one in association with trisomies of chromosomes 7 and 9. An UPD-study for selective chromosomes with homologue regions to mouse chromosomes, which show embryonic or neonatal lethality in UPD status, revealed no case of UPD in 50 spontaneous abortions. ${ }^{16}$ Based on the exclusion of UPD in a relatively small number of 35 cases the incidence of holochromosome UPD in spontaneous abortions was estimated between 0 $10 \% .{ }^{14}$ In our series of 71 foetal losses, we identified two cases of holochromosome UPD, a proportion of $2.8 \%$ within the estimated range. Thus, UPD does not appear to represent a major cause of spontaneous abortions with normal karyotypes. Yet its presence in this group of embryonic losses offers interesting insights into the mechanisms involved.

In our case with $\mathrm{UPhD}(9)$ mat, molecular data indicate that the mechanism involved was trisomy rescue: a trisomic conceptus arose from non-disjunction of maternal meiosis I prior to fertilisation followed by a random loss of the paternal homologue very early in postzygotic embryonic development, thus re-establishing an euploid cell line. However, the question remains whether the prenatal growth retardation of the embryo was due to an imprinting effect by UPhD(9)mat or whether it was associated with placental failure because of a hidden trisomy 9 mosaicism. By our approach it was not possible to detect low level trisomy in the placenta or in the foetus, taking into consideration that trisomic cells, may be confined to only one tissue compartment. ${ }^{17}$ A phenotypic effect of maternal UPD(9) seems to be unlikely since there is no evidence for an imprinting locus on maternal chromosome 9 (Table 3). Therefore, maternal UPD(9) appears to be without major clinical consequences unless a recessive mutation is reduced to homozygosity, ${ }^{18,19}$ whereas trisomy 9 mosaicism results in severe congenital anomalies. ${ }^{20,21}$ In this respect, we believe that the more probable cause for the abortion event in case 1 is not $\operatorname{UPD}(9)$ mat, but purulent chorioamnionits.

In case 2, the findings of isodisomy with homozygosity along the length of chromosome 21 and of paternal origin of UPD suggest that UPiD(21)pat is most likely the result of a monosomic conception due to an error in maternal meiosis followed by postzygotic 'monosomy complementation'. Chromosome 21 nullisomy has been observed in $0.38 \%$ of spermatocytes and in $0.25 \%$ of oocytes. ${ }^{4}$ However, reports on full monosomy 21 in early pregnancy losses are extremely rare. One such case was proven prenatally evidencing a single chromosome 21 of paternal origin. ${ }^{22}$ Monosomy 21 is presumably lethal in early embryogenesis. Yet, postzygotic duplication of the monosomic chromosome could well represent a mechanism to retrieve a monosomic conception. 
Table 3 Clinical findings associated with uniparental disomy of chromosome 9

\begin{tabular}{|c|c|c|c|c|}
\hline Origin & $\begin{array}{l}\text { Molecular } \\
\text { results }\end{array}$ & Clinical phenotype & $\begin{array}{l}\text { Age of mother } \\
\text { at time of } \\
\text { birth (years) }\end{array}$ & Reference \\
\hline UPD(9) mat & isodisomy & 34-year-old healthy woman with isochromosomes of $9 p$ and $9 q$ & 24 & 36 \\
\hline UPD(9)mat & isodisomy/(hetero-) & monozygotic female twins with Leigh syndrome (MIM 256000) & 46 & 19 \\
\hline UPD(9)mat & $\begin{array}{l}\text { isodisomy } \\
\text { iso-/heterodisomy }\end{array}$ & $\begin{array}{l}\text { two patients with cartilage-hair hypoplasia (MIM 250250) and } \\
\text { severe growth retardation }\end{array}$ & $30 / 28$ & 18 \\
\hline $\begin{array}{l}\text { UPD(9)mat } \\
\text { associated with CPM } \\
\text { for trisomy } 9\end{array}$ & iso-/heterodisomy & induced abortion in 10th g.w. & 38 & 37 \\
\hline $\begin{array}{l}\text { UPD(9)mat } \\
\text { associated with CPM } \\
\text { for trisomy } 9 \text { and low } \\
\text { level of trisomy } 9 \text { mosaicism }\end{array}$ & (iso-)/heterodisomy & $\begin{array}{l}\text { minor features of trisomy } 9 \text {, minor skeletal anomalies, normal } \\
\text { development }\end{array}$ & 43 & 38 \\
\hline $\begin{array}{l}\text { UPD(9)mat } \\
\text { associated with low level } \\
\text { of trisomy } 9 \text { mosaicism }\end{array}$ & heterodisomy & $\begin{array}{l}\text { 17-year-old boy with craniofacial dysmorphic features } \\
\text { reminiscent to trisomy } 9 \text {-syndrome, growth retardation, } \\
\text { kyphoscoliosis, skeletal anomalies, mental retardation }\end{array}$ & 30 & 39 \\
\hline $\begin{array}{l}\text { UPD(9)mat } \\
\text { associated with SRC } \\
\text { mosaicism }[\mathrm{r}(9)(\mathrm{p} 10 \mathrm{p} 12)]\end{array}$ & (iso-)/heterodisomy & developmental delay, no obvious dysmorphisms & - & 40 \\
\hline
\end{tabular}

$\mathrm{SRC}=$ supernumerary ring chromosome, $\mathrm{CPM}=$ confined placental mosaicism.

Table 4 Clinical findings associated with uniparental disomy of chromosome 21

\begin{tabular}{|c|c|c|c|c|}
\hline Origin & $\begin{array}{l}\text { Molecular } \\
\text { results }\end{array}$ & Clinical phenotype & $\begin{array}{l}\text { Age of mother } \\
\text { at time of } \\
\text { birth (years) }\end{array}$ & Reference \\
\hline $\begin{array}{l}\text { UPD }(21) \text { mat } \\
\text { in combination with } \\
\text { trisomy } 7 \text { and } 9\end{array}$ & - & $\begin{array}{l}\text { anembryonic pregnancy in 14th g.w., hydropic and avascular } \\
\text { chorionic villi }\end{array}$ & 29 & 15 \\
\hline UPD(21)mat & heterodisomy & anembryonic pregnancy in 8th g.w., normal appearance of chorionic villi & 31 & 15 \\
\hline UPD(21)mat & isodisomy & normal phenotype in a woman with a de novo $(21 \mathrm{q} ; 21 \mathrm{q})$ translocation & - & 29 \\
\hline UPD(21)mat & iso-/heterodisomy & normal phenotype in a male newborn & 38 & 26 \\
\hline $\begin{array}{l}\text { UPD }(21) \text { mat } \\
\text { in association with } \\
\text { trisomy } 21 \text { mosaicism }\end{array}$ & isodisomy & 11-year-old girl with Down-syndrome & 22 & 41 \\
\hline $\begin{array}{l}\text { UPD }(21) \text { mat in } \\
\text { association with del }(21 \mathrm{q}) \\
\text { (compensatory UPD) }\end{array}$ & iso-/heterodisomy & $\begin{array}{l}\text { intrauterine growth failure, developmental delay, microcephaly, } \\
\text { short neck, severe micrognathia, increased muscle tone, } \\
\text { flexion deformities, scoliosis }\end{array}$ & 36 & $42 / 43$ \\
\hline UPD(21)pat & isodisomy & $\begin{array}{l}\text { normal phenotype in a } 40 \text {-year-old man with a de novo }(21 \mathrm{q} ; 21 \mathrm{q}) \\
\text { translocation }\end{array}$ & 29 & 28 \\
\hline UPD(21)pat & isodisomy & normal phenotype in a woman with a de novo $(21 \mathrm{q} ; 21 \mathrm{q})$ translocation & 31 & 27 \\
\hline UPD(21)pat & isodisomy & $\begin{array}{l}\text { intrauterine growth failure, marked dysmorphic features, hydrocephalus, } \\
\text { growth retardation, severe mental retardation, muscular hypertonia }\end{array}$ & 26 & $42 / 43$ \\
\hline
\end{tabular}

However, based on our observations of a low incidence of UPD in spontaneous abortions it seems to be unlikely that most monosomic conceptions survive long enough to be 'rescued' by duplication of the missing chromosome. It is of interest that in our case the father and the mother were 42 and 40 years respectively at the time of conception since advanced parental age is known to increase the risk of nondisjunction as of losses of maternal homologues. .,23-25 $^{-25}$

The phenotypic effect of $\operatorname{UPD}(21)$ remains still unclear (Table 4). Once passing the foetal stage, maternal and paternal UPD(21) seem compatible with a normal phenotype. ${ }^{26-29}$ So far, there is neither evidence of imprinted genes on chromosome 21 nor in the syntenic regions on mouse chromosome 16 . However, the possibility exists that $\operatorname{UPD}(21)$ may show imprinting effects limited to placental tissue and in vitro growth which would explain the anlage defect in our case. Genomic imprinting could be specific to developmental stages, promotor specific or tissue specific, as recently described by brain specific imprinting of the UBE3A-gene in Angelman syndrome. ${ }^{30}$

The exact timing of aneuploidy correction is still unclear. Assuming that aneuploidy correction occurs only once, our data suggest that in our collective any somatic aneuploidy correction would have taken place very early, prior to the differentiation of chorion and the embryonic progenitor in the inner cell mass. However, recent data on UPD cases with meiotic confined placental mosaicism (CPM) and with high levels of mosaicism or full trisomy in chorionic villi point to 
rescue mechanisms at later developmental stages. ${ }^{5}$ In addition, a skewed pattern of X-inactivation has been found in cases with meiotic CPM related to the successful elimination of trisomy reducing the foetus to only one or few diploid precursors in the late blastocyst stage. ${ }^{31}$ Non random X-inactivation was also detected in $25 \%$ of maternal UPD 15 cases. $^{32}$ Furthermore, recent data on human preimplantation embryos show a high rate of mosaic aneuploidy not only in the two to eight cell stage embryo ${ }^{11}$ but also in the inner cell mass (ICM) cell lineages in enhanced-hatching blastocyst. ${ }^{33}$ It, therefore, appears that rescue mechanisms of postzygotic non-disjunctions occur at a later developmental stage in the majority of cases. Results in our highly selected collective, however, indicate that aneuploidy correction of meiotic non-disjunction can already set in at early postzygotic cleavage stages, potentially depending on maternal transcripts accumulated during oogenesis. $^{34}$

In conclusion, the incidence of UPD in a series of consecutive spontaneous abortions with normal karyotpes is very low $(2.8 \%)$. However, the impact of UPD on defects in embryonic development may still be higher than concluded from the present study since increasing numbers of segmental UPDs have recently been reported possibly occurring in highly recombinant regions or instable areas of chromosomal attachment during meiosis (for review see ${ }^{35}$ ). Such cases would be likely to escape our holochromosomal UPD approach. In our closely selected study collective we could find evidence that chromosomal aneuploidy correction can occur only occasionally in the very early cleavage stages. To further clarify timing and mechanisms involved, investigations should be performed into a group of abortion cases including CPM cases.

\section{Acknowledgments}

We express our appreciation to all the couples who agreed to participate in our study, at a time of personal distress. We thank their physicians for their cooperation, particularly Dr Hoffmann, Diakonie Krankenhaus Wehrda, Marburg. The technical assistance of Maritha Lippmann (Marburg), Madeleine Skorna (Berlin) and Marga Schepens (Nijmegen) is gratefully acknowledged. We thank Dr J Köhler for critical suggestions concerning the manuscript. Large scale PCR analysis was done at the Max Delbrück-Center, Berlin. This work was supported by a grant from the Deutsche Forschungsgemeinschaft DFG (Re 429/8-1/Fr 1302/1-2).

\section{References}

1 Robinson WP: Mechanisms leading to uniparental disomy and their clinical consequences. BioEssays 2000; 22: 452-459.

2 Kotzot D: Abnormal phenotypes in uniparental disomy (UPD): Fundamental aspects and a critical review with bibliography of UPD other than 15. Am J Med Genet 1999; 82: $265-274$

3 Guttenbach M, Engel W, Schmid M: Analysis of structural and numerical chromosome abnormalities in sperm of normal men and carriers of constitutional chromosome aberrations. A review. Hum Genet 1997; 100: 1-21.
4 Martin RH, Ko E, Rademaker AW: Distribution of aneuploidy in human gametes: Comparison between human sperm and oocytes. Am J Med Genet 1991; 39: 321 - 331.

5 Robinson WP, Barrett IJ, Bernard L et al: Meiotic origin of trisomy in confined placental mosaicism is correlated with presence of fetal uniparental disomy, high levels of trisomy in trophoblast and increased risk of fetal intrauterine growth retardation. Am J Hum Genet 1997; 60: 917 - 927.

6 Wolstenholme J: Confined placental mosaicism for trisomies 2, $3,7,8,9,16$, and 22: their incidence, likely origins, and mechanisms for cell lineage compartmentalization. Prenat Diagn 1996; 16: $511-524$.

7 Kalousek DK, Barrett I: Genomic imprinting related to prenatal diagnosis. Prenat Diagn 1994; 14: 1191-1201.

8 Ledbetter DH, Engel E: Uniparental disomy in humans: development of an imprinting map and its implications for prenatal diagnosis. Hum Mol Genet 1995; 4: 1757-1764.

9 Preece MA, Moore GE: Genomic imprinting, uniparental disomy and foetal growth. TEM 2000; 11: 270-275.

10 Fritz B, Hallermann C, Olert J et al: Cytogenetic analyses of culture failures by comparative genomic hybridization (CGH). Re-evaluation of chromosome aberration rates in early spontaneous abortions. Eur J Hum Genet 2001; 9: 539-547.

11 Munné S, Grifo J, Alikani M, Cohen J, Tomkin J: Embryo morphology, developmental rates, and maternal age are correlated with chromosome abnormalities. Fertility and Sterility 1995; 64: 382-391.

12 Boué A, Boué J, Gropp A: Cytogenetics of pregnancy wastage. Adv Hum Genet 1983; 14: 1-57.

13 Shaffer LG, McCaskill C, Adkins K, Hassold TJ: Systematic search for uniparental disomy in early fetal losses: The result and a review of the literature. Am J Med Genet 1998; 79: 366-372.

14 Smith MJ, Creasy MR, Clarke A, Upadhyaya M: Sex ratio and absence of uniparental disomy in spontaneous abortions with a normal karyotype. Clin Genet 1998; 53: 258-261.

15 Henderson DJ, Sherman LS, Loughna SC, Bennett PR, Moore GE: Early embryonic failure associated with uniparental disomy for human chromosome 21. Hum Mol Genet 1994; 3: $1373-1376$.

16 Nazarenko SA, Nikitina TV: Search for uniparental disomy in spontaneous abortions from Russian population of West Sibiria. Cytogenet Cell Genet 1999; 85: 158.

17 Benn P: Trisomy 16 and trisomy 16 mosaicism: A review. Am Med Genet 1998; 79: 121-133.

18 Sulisalo T, Makitie O, Sistonen P et al: Uniparental disomy in cartilage-hair hypoplasia. Eur J Hum Genet 1997; 5: 35 - 42.

19 Tiranti V, Lamantea E, Uziel G et al: Leigh syndrome transmitted by uniparental disomy of chromosome 9. J Med Genet 1999; 36: 927-928.

20 Arnold GL, Kirby RS, Stem TP, Sawyer JR: Trisomy 9: review and report of two new cases. Am J Med Genet 1995; 56: 252-257.

21 Wooldridge J, Zunich J: Trisomy 9 syndrome: report of a case with Crohn disease and review of the literature. Am J Med Genet 1995; 56: 258-264.

22 Joosten AMS, De Vos S, van Obstal D et al: Full monosomy 21, prenatally diagnosed by fluorescent in situ hybridization. Prenat Diagn 1994; 3: 271-275.

23 Hassold T, Abruzzo M, Adkins $\mathrm{K}$ et al: Human aneuploidy: incidence, origin and etiology. Environ Mol Mutagen 1996; 28 : $167-175$.

24 Robinson WP, Langlois S, Schuffenhauer S et al: Cytogenetic and age-dependent risk factors associated with uniparental disomy 15. Prenat Diagn 1996; 16: 837-844.

25 Ginsburg C, Fokstuen S, Schinzel A: The contribution of uniparental disomy to congenital development defect in children born to mothers at advanced childbearing age. Am J Med Genet 2000; 95: $454-460$.

26 Rogan PK, Sabol DW, Punnett HH: Maternal uniparental disomy of chromosome 21 in a normal child. Am J Med Genet 1999; 83: 69-71. 
27 Robinson WP, Bernasconi F, Basaran S et al: A somatic origin of homologous Robertsonian translocations and isochromosomes. Am J Hum Genet 1994; 54: 290-302.

28 Blouin JL, Avramopoulos D, Pangalos C, Antonarakis SE: Normal phenotype with paternal uniparental isodisomy for chromosome 21. Am J Hum Genet 1993; 53: 1074-1078.

29 Créau-Goldberg N, Gegonne A, Delabar J et al: Maternal origin of a de novo balanced $\mathrm{t}(21 \mathrm{q} 21 \mathrm{q})$ identified by ets- 2 polymorphism. Hum Genet 1987; 76: 396-398.

$30 \mathrm{Vu} \mathrm{TH}$, Hoffman AR: Imprinting of the Angelman syndrome gene, UBE3A, is restricted to brain. Nat Genet 1997; 17: 12-13.

31 Lau AW, Brown CJ, Langlois S, Kalousek DK, Robinson WP: Skewed X-inactivation is common in fetuses or newborns associated with confined placental mosaicism. Am J Med Genet 1997; 61: $1353-1361$.

32 Robinson WP, Christian BD, Kuchinka BD et al: Somatic segregation errors predominantly contribute to the gain or loss of a paternal chromosome leading to uniparental disomy for chromosome 15. Clin Genet 2000; 57: 349-358.

33 Magli MC, Jones GM, Gras L, Gianaroli L, Korman I, Trounson AO: Chromosome mosaicism in day 3 aneuploid embryos that develop to morphologically normal blastocysts in vitro. Hum Reprod 2000; 15: 1781-1786.

34 Handyside AH, Delhanty JAD: Preimplantation genetic diagnosis: strategies and surprises. TIG 1997; 13: 270-275.

35 Kotzot D: Complex and segmental uniparental disomy (UPD): review and lessons from rare chromosomal complements. J Med Genet 2001; 38: 497-507.

36 Björck EJ, Anderlid BM, Blennow E: Maternal isodisomy of chromosome 9 with no impact on the phenotype in a woman with two isochromosomes: i(9p) and i(9q). Am J Med Genet 1999; 87: $49-52$.
37 Wilkinson TA, James RS, Crolla JA, Cockwell AE, Campbell PL, Temple IK: A case of maternal uniparental disomy of chromosome 9 in association with confined placental mosaicism for trisomy 9. Prenat Diagn 1996; 16: 371-374.

38 Slater HR, Ralph A, Daniel A, Worthington S, Roberts C: A case of maternal uniparental disomy of chromosome 9 diagnosed prenatally and the related problem of residual trisomy. Prenat Diagn 2000; 20: 930-932.

39 Willatt LR, Clare Davison BC, Goudie D et al: A male with trisomy 9 mosaicism and maternal uniparental disomy for chromosome 9 in the euploid cell line. J Med Genet 1992; 29 $742-744$.

40 Anderlid BM, Sahlen S, Schoumans J et al: Detailed characterization of 12 supernumerary ring chromosomes using micro-FISH and search for uniparental disomy. Am J Med Genet 2001; 99: $223-233$

41 Bruyère H, Rupps R, Kuchinka BD, Friedman JM, Robinson WP: Recurrent trisomy 21 in a couple with a child presenting trisomy 21 mosaicism and maternal uniparental disomy for chromosome 21 in the euploid cell line. Am J Med Genet 2000; 94: 35 41.

42 Bartsch O, Petersen MB, Stuhlmann I et al: 'Compensatory' uniparental disomy of chromosome 21 in two cases. J Med Genet 1994; 31: 534-540.

43 Petersen MB, Bartsch O, Adelsberger PA et al: Uniparental isodisomy due to duplication of chromosome 21 occurring in somatic cells monosomic for chromosome 21. Genomics 1992; 13: $269-274$. 